\author{
SERIES 'CLINICAL PHYSIOLOGY IN RESPIRATORY INTENSIVE CARE' \\ Edited by A. Rossi and C. Roussos
}

Number 16 in this Series

\title{
Acute severe asthma: pathophysiology and pathobiology of gas exchange abnormalities
}

\author{
R. Rodriguez-Roisin
}

\begin{abstract}
Acute severe asthma: pathophysiology and pathobiology of gas exchange abnormalities. R. Rodriguez-Roisin. OERS Journals Ltd 1997.

ABSTRACT: Acute severe asthma, or "status asthmaticus", is a devastating clinical condition ultimately resulting in life-threatening hypoxaemia. The pivotal intrapulmonary mechanism of this condition is profound ventilation/perfusion $\left(V^{\prime} \mathrm{A} / Q^{\prime}\right)$ mismatch, characterized by a predominant bimodal blood flow pattern reflecting a marked deterioration (increase) of the dispersion of pulmonary blood flow. This $V^{\prime} \mathrm{A} / Q^{\prime}$ profile is consistent with the presence of numerous alveolar units with low $V^{\prime} \mathrm{A} / Q$ ' ratios, in which ventilation is markedly reduced, although never abolished, but perfusion is maintained. Further $V^{\prime} \mathrm{A} / Q$ ' worsening whilst breathing $100 \% \mathrm{O}_{2}$ suggests the presence of an underlying vigorous hypoxic vascular response. Of equal importance, gas exchange disturbances are poorly related to the severity of reduced maximal airflow rates.

Inhaled platelet-activating factor (PAF), both in normal individuals and asthmatic patients, results in moderate-to-severe disturbance of $V^{\prime} \mathrm{A} / Q^{\prime}$ status, a finding that is probably related to altered microvascular permeability within the airway wall. Salbutamol, but not ipratropium bromide, prevented all PAF-induced systemic and lung function abnormalities, possibly because venoconstriction in the bronchial circulation was antagonized. Taken together, these findings support the hypothesis that platelet-activating factor may play a critical role in the pathobiology of severe acute exacerbations of asthma.
\end{abstract}

Eur Respir J 1997; 10: 1359-1371.

Servei de Pneumologia i Al.lèrgia Respiratòria, Dept de Medicina, Hospital Clínic, Universitat de Barcelona, Barcelona, Spain

Correspondence: R. Rodriguez-Roisin, Servei de Pneumologia i Al. lèrgia Respiratòria, Dept de Medicina, Hospital Clínic, Universitat de Barcelona, Barcelona, Spain

Keywords: Airway mediators, anti-asthma drugs, bronchial circulation, fatal and near-fatal asthma, platelet activating factor, ventilation-perfusion mismatching

Received: April 81997

Accepted for publication April 161997

Supported by Grants from the Comissionat per a Universitats i Recerca (1995 SGR 00446) de la Generalitat de Catalunya and the Fondo de Investigación Sanitaria (FIS) $97 / 0126$.
Bronchial asthma is a chronic disease that causes widespread narrowing of the conducting airways. It is universally accepted that short-term variability of airway narrowing is the hallmark of bronchial asthma. Airway inflammation and bronchial hyperresponsiveness, together with airflow obstruction, are pivotal pathogenetic components of asthma and have been included in its current definition. Although airway inflammation and reactivity are not unique to asthma and may be common in other chronic airway conditions, the critical issue in bronchial asthma is the specific type of airway inflammation and its interplay with airway responsiveness.

In patients with asthma, during acute attacks, arterial oxygen and carbon dioxide $\left(\mathrm{Pa}, \mathrm{O}_{2}\right.$ and $\left.\mathrm{Pa}_{\mathrm{a}}, \mathrm{CO}_{2}\right)$ values can range from nearly normal or slightly abnormal to extremely altered, ultimately resulting in profound hypox- aemia with or without hypercapnia [1]. All asthmatic patients are susceptible and at risk of developing acute severe asthma (ASA) (status asthmaticus), a life-threatening condition leading to impending acute severe respiratory failure and even, to death [2]. Near-fatal or fatal asthma is a catastrophic, devastating clinical condition that occurs despite increased understanding of its pathophysiology and pathogenesis, a better awareness of the main therapeutic guidelines, and important current achievements in the preventive and educational aspects of asthma.

\section{Clinical framework}

One important, but difficult, question to answer is how and why asthmatic patients die during an episode of severe exacerbation, particularly outside a medical

Previous articles in this series: No. 1: S.K. Pingleton. Enteral nutrition in patients with respiratory disease. Eur Respir J 1996; 9: 364-370. No. 2: R. Dhand, M.J. Tobin. Bronchodilator delivery with metered-dose inhalers in mechanically-ventilated patients. Eur Respir J 1996; 9: 585-595. No. 3: N. Ambrosino. Noninvasive mechanical ventilation in acute respiratory failure. Eur Respir J 1996; 9: 795-807. No. 4: P. Pelosi, S. Crotti, L. Brazzi, L. Gattinoni. Computed tomography in adult respiratory distress syndrome: what has it taught us? Eur Respir J 1996; 9: 1055-1062. No. 5: H. Burchardi. New strategies in mechanical ventilation for acute lung injury. Eur Respir J 1996; 9: 1063-1072. No. 6: V.M. Ranieri, M. Dambrosio, N. Brienza. Intrinsic PEEP and cardiopulmonary interactions in patients with COPD and acute ventilatory failure. Eur Respir J 1996; 9: 1283-1292. No. 7: A. Corrado, M. Gorini, G. Villella, E. De Paola. Negative pressure ventilation in the treatment of acute respiratory failure: an old noninvasive technique reconsidered. Eur Respir J 1996; 9: 1531-1544. No. 8: A. Torres, M. El-Ebiary, N. Soler, C. Montón, N. Fàbregas, C. Hernández. Stomach as a source of colonization of the respiratory tract during mechanical ventilation: association with ventilator-associated pneumonia. Eur Respir J 1996; 9: 1729-1735. No. 9: J. Mancebo. Weaning from mechanical ventilation. Eur Respir J 1996; 9: 1923-1931. No. 10: D. Georgopoulos, C. Roussos. Control of breathing in mechanically ventilated patients. Eur Respir J 1996; 9: $2151-2160$. No. 11: T. Vassilakopoulos, S. Zakynthinos, Ch. Roussos. Respiratory muscles and weaning failure. Eur Respir J 1996; 9: 2383-2400. No. 12: G.U. Meduri. The role of the host defence response in the progression and outcome of ARDS: pathophysiological correlations and response to glucocorticoid treatment. Eur Respir $J$ 1996; 9: 2650-2670. No. 13: H.E. Fessler. Heart-lung interactions: applications in the critically ill. Eur Respir J 1997; 10: 226-237. No. 14: S. Singh, T.W. Evans. Nitric oxide, the biological mediator of the decade: fact or fiction. Eur Respir J 1997; 10: 699-707. No. 15: W.T. McNicholas. Impact of sleep in respiratory failure. Eur Respir J 1997; 10: 920-933. 
environment. Conceivably, the mechanisms involved may be multifactorial. However, in a study of 10 patients with asthma, who reached the hospital in respiratory arrest or had overt respiratory failure within less than 30 min after admission to the casualty room in spite of vigorous conventional medical therapy, Molfino et al. [3] postulated that the near-fatal nature of these exacerbations was the result of severe asphyxia. At the time of respiratory arrest, while oxygen was given by T-tube or breathing bag mask, these patients exhibited extreme hypercapnia, $P \mathrm{a}, \mathrm{CO}_{2}>8.0 \mathrm{kPa}(60 \mathrm{mmHg})$ in all cases, and intense mixed acidosis. It was concluded that the near-fatal nature of these episodes of ASA was the result of severe asphyxia, i.e. unconsciousness or death resulting from lack of oxygen, rather than cardiac arrhythmias related to the side-effects of antiasthma drugs, more specifically $\beta_{2}$-agonists. The asphyxia or hypoxaemia hypothesis, previously suggested by others [4], would point to undertreatment rather than overtreatment, which had been indicated by detrimental cardiac effects as one of the principal factors implicated in the increased number of patients with fatal asthma.

How common are abnormal arterial blood gas tensions in patients with ASA? A review based on the analysis of routine gas exchange data in over 350 critically sick patients in the 1970 s revealed that only $2 \%$ had $\mathrm{Pa}, \mathrm{O}_{2}$ values $<6.7 \mathrm{kPa}(50 \mathrm{mmHg})$, while $13 \%$ of patients had a $P$ a, $\mathrm{CO}_{2}$ of $6.0-8.0 \mathrm{kPa}(45-60 \mathrm{mmHg})$ and only $4 \%$ of patients $>8.0 \mathrm{kPa}(60 \mathrm{mmHg})$ [2]. Nevertheless, the clinical severity of the attacks was variable, with no uniform criteria among the different reports published. For instance, in a more recent study in patients with ASA, within the first $24 \mathrm{~h}$ of their admission to the hospital, five out of ten patients (of whom only one required mechanical ventilation) had $\mathrm{Pa}, \mathrm{O}_{2}$ values $<6.7 \mathrm{kPa}(50$ $\mathrm{mmHg}$ ) and two had $\mathrm{Pa}, \mathrm{CO}_{2}$ levels $>6.0 \mathrm{kPa}(45 \mathrm{mmHg})$ whilst breathing room air [5]. In another study [6], including 18 patients with $\mathrm{ASA}, \mathrm{Pa}_{\mathrm{a}} \mathrm{O}_{2}$ was $<6.7 \mathrm{kPa}(50$ $\mathrm{mmHg}$ ) in two patients and $\mathrm{Pa}, \mathrm{CO}_{2}>6.0 \mathrm{kPa}(45 \mathrm{mmHg})$ in two out of nine patients admitted to hospital (within less than $6 \mathrm{~h}$ ) under similar breathing conditions. Patients with ASA presenting with hypercapnia when attending the hospital had features of more severe persistent asthma and more severe airway narrowing; had a longer duration of asthma; were more prone to require maintenance treatment both with $\beta$-adrenergic agonists and steroids; and were less likely to have been previously in and discharged from the emergency room [7]. These data are compatible with the view that hypercapnia in ASA can evolve rapidly, and is not necessarily related to a prolonged attack.

Patients with sudden "asphyxic" asthma, defined as a rapidly progressing attack associated with extreme respiratory failure needing mechanical support very quickly (within less than $3 \mathrm{~h}$ of the onset of symptoms) [8], show a severe mixed acidosis with intense hypercapnia. This condition may be caused either by massive inhalation of airborne soybean dust [9] or thunderstorm activity [10], or associated with sensitivity and exposure to other allergens, such as Alternaria alternata [11], or a stressful event, with a higher incidence of respiratory arrest but a more rapid remission, with a shorter duration of mechanical ventilation. These fulminant, calamitous, dismal presentations of ASA have been categorized by SuR et al. [12] as "sudden-onset" fatal asthma, as opposed to the more common "slow-onset" form, to highlight a different aetiopathogenic mechanism and, possibly, a specific underlying structural derangement of the airway.

Respiratory alkalosis is the most common acid-base abnormality in severe acute conditions, although, as asthma worsens, this results in respiratory or mixed acidosis due to hypercapnia and associated lactic acidosis in peripheral tissues. Patients with more severe $\mathrm{CO}_{2}$ retention $\left(P \mathrm{a}, \mathrm{CO}_{2}>12.0 \mathrm{kPa}(90 \mathrm{mmHg})\right)$ and respiratory acidosis $(\mathrm{pH}<7.0)$ can show dramatic subconjunctival haemorrhage, possibly due to sudden and severe congestion of blood flow into the territory of the superior vena cava, resulting from raised intrathoracic airway pressures in order to overcome massive and widespread airway narrowing [13]. Although not common, its presentation should alert physicians as a sign of impending ASA.

Similarly, patients with an acute exacerbation of asthma, who have become profoundly hypercarbic and hypoxaemic, may have critically raised intracranial pressure [14]. It has recently been proposed that acute intracranial pressure-induced uncal herniation and third cranial nerve palsy, causing a single dilated pupil, can be developed by a combination of acute hypercapnia, cerebral hypoxia and high intrathoracic pressures. It can be expected that extreme hypercapnia would create maximal cerebral vasodilation, hence increasing intracranial volume and causing hypoxaemia, acidosis, marked cellular swelling and, as a consequence of elevated intrathoracic pressure, limitation of cerebral venous drainage [14].

In many historical studies using respiratory gas tension $[15,16]$, a positive linear relationship has been shown between $\mathrm{Pa}_{\mathrm{a}} \mathrm{O}_{2}$, or a hyperbolic relationship between $P$ a, $\mathrm{CO}_{2}$, and forced expiratory volume in one second (FEV1). However, FEV1 above $1.0 \mathrm{~L}$ is not a reliable predictor of the $\mathrm{Pa}_{\mathrm{a}} \mathrm{O}_{2}$, and this is also true for the relationship between $\mathrm{Pa}_{\mathrm{a}} \mathrm{CO}_{2}$ and $\mathrm{FEV}$. In principle, the

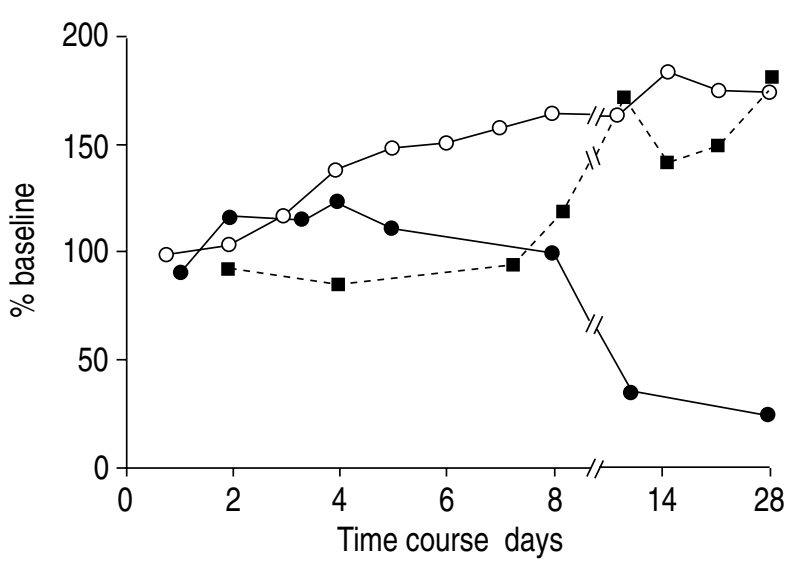

Fig. 1. - Time course of changes in $\mathrm{FEV}_{1}\left(-\mathrm{O}_{-}\right), \mathrm{Pa}_{\mathrm{a}, \mathrm{O}_{2}}(--\cdots)$ and $V^{\prime} \mathrm{A} / Q^{\prime}$ mismatch (- $)$ (as assessed by the dispersion of pulmonary blood flow), expressed as percentage of change from admission, in a representative patient with ASA while breathing room air. Note that the improvement of $\mathrm{FEV} 1$ precedes that of $P_{\mathrm{a}, \mathrm{O}_{2}}$ and $V^{\prime} \mathrm{A} / Q^{\prime}$ imbalance. FEV 1 increases immediately and progressively during hospitalization, whereas the two gas exchange indices remain unchanged, to markedly improve after discharge. This pattern was shown in 7 of the 8 patients studied. FEV1: forced expiratory volume in one second; $P \mathrm{a}, \mathrm{O}_{2}$ : arterial oxygen tension; $V^{\prime} \mathrm{A} / Q^{\prime}$ : alveolar ventilation/perfusion; ASA: acute severe asthma. (Taken with permission from [5]). 
greater the airway obstruction the worse the gas exchange; and yet this need not be the case. In a sequential study of patients with ASA, we identified a complete dissociation between airflow rates and gas exchange markers, both while admitted to hospital and during remission after discharge [5]. Moreover, airflow rates recovered more readily than gas exchange disturbances during hospitalization, the latter improving only after discharge (fig. 1). Similarly, in children admitted to hospital for ASA, arterial $\mathrm{O}_{2}$ saturation $\left(\mathrm{Sa}_{\mathrm{a}} \mathrm{O}_{2}\right)$ is low at admission, and reflects bronchodilation with salbutamol only when $\mathrm{O}_{2}$ saturation is low. $\mathrm{Sa}, \mathrm{O}_{2}$ recovers more slowly than airway function, and also more quickly in younger children than in older children [17]. Lack of improvement or worsening of gas exchange [18], whilst airflow rates increase following the conventional administration of different classes of bronchodilators in patients with ASA, is further compelling evidence of this intriguing dissociation of behaviour between spirometry and pulmonary gas exchange.

\section{Pathophysiology}

In recent years, there has been major progress in understanding the pathophysiological mechanisms of pulmonary gas exchange in bronchial asthma, largely through the information provided by the multiple inert gas elimination technique (MIGET), a robust tool for the quantitative and qualitative assessment of the distribution of $V^{\prime} \mathrm{A} / Q^{\prime}$ ratios in the lung $[1,19]$. Of equal importance, MIGET provides a quantum leap forward to unravelling the complex interaction among the different intrapulmonary determinants, namely $V^{\prime} \mathrm{A} / Q^{\prime}$ imbalance, increased intrapulmonary shunt and alveolar-to-endcapillary diffusion limitation to $\mathrm{O}_{2}$, and extrapulmonary determinants (essentially inspired $\mathrm{O}_{2}$ fraction $\left(F \mathrm{I}, \mathrm{O}_{2}\right)$, overall ventilation, cardiac output and $\mathrm{O}_{2}$ consumption) that modulate the physiological blood gas values in the clinical arena [19].

At present, it is largely undisputed that $V^{\prime} \mathrm{A} / Q^{\prime}$ mismatch is the pivotal mechanism leading to abnormal arterial blood gas values, being the primary factor that modulates the varying levels of arterial hypoxaemia. Carbon dioxide retention during ASA can also be, in part, associated with $V^{\prime} \mathrm{A} / Q^{\prime}$ inequality, although it is likely that alveolar hypoventilation related to respiratory muscle fatigue and/or weakness can also play a key role. However, detecting respiratory fatigue in patients with critically life-threatening asthma is not easy with the technology currently available. By contrast, both increased intrapulmonary shunting and alveolar-to-endcapillary diffusion limitation to $\mathrm{O}_{2}$, the two other intrapulmonary factors influencing pulmonary gas exchange, are conspicuously marginal.

A wide variety of $V^{\prime} \mathrm{A} / Q^{\prime}$ inequalities has been demonstrated in the different categories of asthma. At one end of the spectrum, patients with mild-to-moderate asthma may have nearly normal, mildly broadened unimodal distributions of the pulmonary perfusion, hence increasing the dispersion of blood flow, i.e. a functional outcome of $V^{\prime} \mathrm{A} / Q^{\prime}$ inequality sensitive to areas of both below normal and low $V^{\prime} \mathrm{A} / Q^{\prime}$ ratio, with normal or nearly normal $\mathrm{Pa}_{\mathrm{a}} \mathrm{O}_{2}$ and a normal or slightly decreased
$P \mathrm{a}, \mathrm{CO}_{2}$, but increased values of alveolar-arterial difference in oxygen tension $\left(P(\mathrm{~A}-\mathrm{a}), \mathrm{O}_{2}\right)$ values $[1,20]$. This is due to the buffering effect that an inordinately high cardiac output, which is a distinctive feature of many critically ill asthmatic patients, has on $\mathrm{Pa}_{\mathrm{a}} \mathrm{O}_{2}$ [20]. Alternatively, patients with life-threatening ASA, with [21] or without $[5,6,18]$ the need for mechanical ventilation, exhibit the most grossly abnormal profile of the $V^{\prime} \mathrm{A} / Q^{\prime}$ spectrum, namely a bimodal pattern of the pulmonary blood flow distribution (fig. 2). Accordingly, a

a)

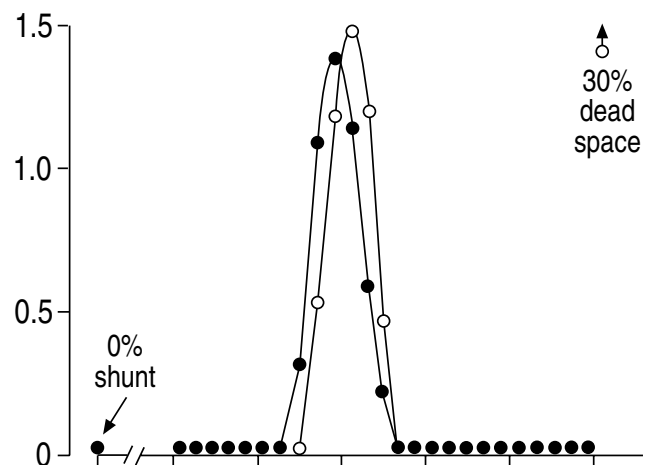

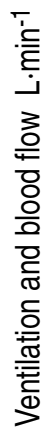

b)

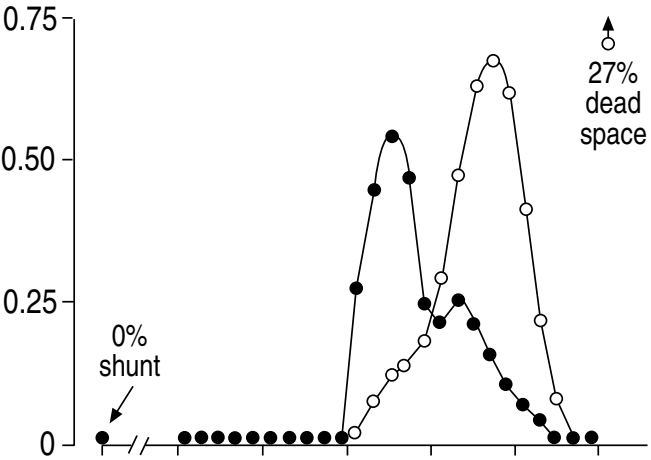

c)

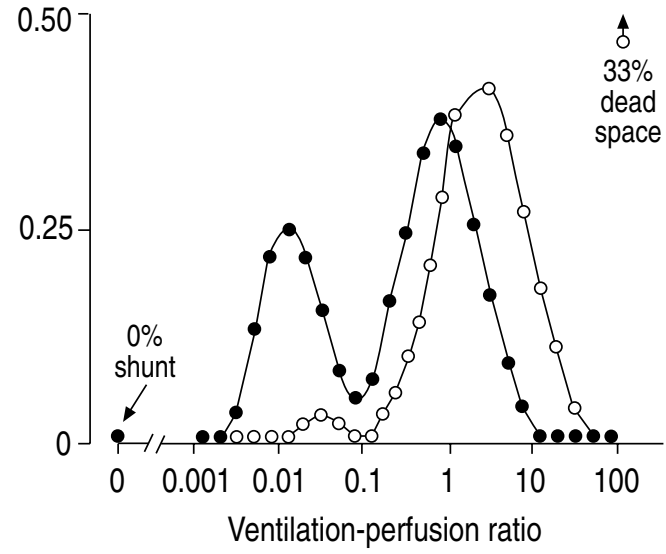

Fig. 2. - Three profiles of $V^{\prime} \mathrm{A} / Q^{\prime}$ distribution plotted against a $V^{\prime} \mathrm{A} /$ $Q^{\prime}$ ratio on a $\log$ scale while breathing room air $\left(F_{\mathrm{I}, \mathrm{O}_{2}} 0.40\right.$, during mechanical support): a) normal; b) ASA while breathing spontaneous; c) ASA during mechanical ventilation. The narrowing unimodal, well-centred and symmetrical distribution in a healthy young individual differs from the predominant bimodel blood flow pattern of the two patients with ASA. The dispersion of ventilation is discretely broadened, intrapulmonary shunt is conspicuously lacking, and dead space is normal in the abnormal $V^{\prime} \mathrm{A} / Q^{\prime}$ distributions. Note that there are no major $V^{\prime} \mathrm{A} / Q^{\prime}$ profile differences between the two latter. $F_{\mathrm{I}, \mathrm{O}_{2}}$ : inspired oxygen fraction. For further definitions see legend to figure $1 . \longrightarrow-$ : ventilation; $\longrightarrow$ : blood flow. (Taken with permission from $[16,19])$ 
large percentage of cardiac output is distributed to alveolar units with poor or very poor $V^{\prime} \mathrm{A} / Q^{\prime}$ ratios, in keeping with the presence of numerous alveoli in which ventilation is moderately to extremely reduced, although always patent, while perfusion is preserved or even increased. In between, there can be patients with moderate-to-severe persistent categories of asthma [1] with varying degrees of $V^{\prime} \mathrm{A} / Q^{\prime}$ heterogeneity, albeit always affecting the dispersion of pulmonary perfusion more profoundly, according to the underlying severity of the structural derangement.

In general, the more severe the attack of asthma the worse the $V^{\prime} \mathrm{A} / Q^{\prime}$ imbalance. Accordingly, patients with stable asthma, either with intermittent or persistent forms, have broadened unimodal pattern of pulmonary blood flow [1], whilst those presenting with acute severe or fulminant forms [21] generate a predominantly bimodal blood flow profile as the most distinctive $V^{\prime} \mathrm{A} / Q^{\prime}$ pattern. However, it is likely that the high inspired $\mathrm{O}_{2}$ concentrations that may, at least in part, mitigate hypoxic pulmonary vasoconstriction (HPV), and the added pharmacological effects of high doses of $\beta$-adrenergic agonists and methylxanthines, with potential pulmonary vasodilating effects, may both contribute to an increase in the presence of areas with low $V^{\prime} \mathrm{A} / Q^{\prime}$ ratios. Teleologically, HPV is a phenomenon that minimizes the amount of $V^{\prime} \mathrm{A} / Q^{\prime}$ heterogeneity, and hence the ensuing hypoxaemia. Conceivably, in patients with severe persistent asthma, the severity of widespread airway narrowing is akin to a small $V^{\prime} \mathrm{A} / Q^{\prime}$ mismatch, because distal small airways may be either remodelled or distressed by less inflammatory changes or have a more vigorous HPV, or both [1]. In contrast, in ASA, the airway inflammatory involvement may be more dynamic and probably located both proximally and distally, hence resulting in a preferentially bimodal pattern of pulmonary perfusion.

In a canine model of multiple airway occlusion, LEE et al. [22] showed that when small airways $(1.6 \mathrm{~mm}$ in diameter) are occluded, collateral ventilation to distal alveolar units is so efficient that ventilation is only slightly altered; however, as occlusion becomes more proximal, collateral ventilation is less effective until, with beads $4.8 \mathrm{~mm}$ in diameter, the ventilation of distal units is so poor that a bimodal $V^{\prime} \mathrm{A} / Q^{\prime}$ pattern develops. Although anatomical differences between human and dog lung need to be considered, these experimental findings suggest that the bimodal blood flow profile seen in human asthma concurs with near complete obstruction of some airways, and that the levels of airway narrowing may affect the $V^{\prime} \mathrm{A} / Q^{\prime}$ pattern.

A cardinal point of clinical interest is that, irrespective of the extent of $V^{\prime} \mathrm{A} / Q^{\prime}$ abnormalities, whilst breathing room air or low $F \mathrm{I}_{2} \mathrm{O}_{2}$, the presence of increased intrapulmonary shunt is always trivial, even in the most life-threatening conditions of ASA. The distribution (dispersion) of alveolar ventilation, representing basically lung regions above normal and high $V^{\prime} \mathrm{A} / Q^{\prime}$ ratio, is minimally increased (impaired), at least compared to the deterioration of the distribution of blood flow, and inert dead space is not increased.

During severe acute exacerbations or even under stable clinical conditions, patients with chronic obstructive pulmonary disease (COPD) may exhibit a similar low $V^{\prime} \mathrm{A} / Q^{\prime}$ pattern. However, with mild-to-moderate increases of intrapulmonary shunting (in general, below $5 \%$ of cardiac output), it is not uncommon to observe the presence of high $V^{\prime} \mathrm{A} / Q^{\prime}$ units, alone or combined with the former profile, possibly influenced by underlying gas-trapping, lung hyperinflation, intrinsic positive end-expiratory pressure (PEEPi), and also areas of pulmonary emphysema [23].

Overall, $V^{\prime} \mathrm{A} / Q^{\prime}$ inequalities in patients with ASA concur with the historical concept of gas exchange abnormalities [15]. In the classical three-compartment lung model, the effects both of an increased venous admixture ratio $\left(Q^{\prime} \mathrm{S} / Q^{\prime} \mathrm{T}\right)$ and physiological dead space/tidal volume ratio $(V \mathrm{D} / V \mathrm{~T})$ were considered to reflect the gross extent of the underlying $V^{\prime} \mathrm{A} / Q^{\prime}$ abnormalities. The increased $Q$ 's $/ Q^{\prime}$ 'T keeps pace with the presence of increased areas of low $V^{\prime} \mathrm{A} / Q^{\prime}$ ratios, i.e. increased dispersion of pulmonary blood flow. However, while the virtual absence of areas of high $V^{\prime} \mathrm{A} / Q^{\prime}$ ratio, including inert dead space, is consistent with previous studies in adult asthma, this is an unexpected feature in patients with ASA, in whom gas-trapping, with increased intraalveolar pressures induced by check-valve mechanisms, could be present. Hyperinflation would reduce perfusion of such lung areas, thus inducing the development of areas with high $V^{\prime} \mathrm{A} / Q^{\prime}$ ratio, by causing formation of West's zones 1, where alveolar pressure exceeds pulmonary capillary pressure [24].

At first glance, inert dead space is always slightly lower than that calculated with the Bohr equation, because the latter does not include the dead space-like effects of lung units with a carbon dioxide tension $\left(\mathrm{PCO}_{2}\right)$ less than the $P \mathrm{a}, \mathrm{CO}_{2}$ [19]. Increased overall ventilation augments physiological dead space, other things being equal. However, the absence of an increased inert dead space shown in ASA still remains elusive. High $V^{\prime} \mathrm{A} / Q^{\prime}$ regions have been demonstrated only in children with low FEV1 after exercise-induced asthma [25], the contention being that both gas-trapping and lung hyperinflation would provoke areas of high $V^{\prime} \mathrm{A} / Q^{\prime}$ ratio.

Because arterial hypoxaemia is essentially provoked by $V^{\prime} \mathrm{A} / Q^{\prime}$ mismatching, a clinical implication of practical relevance is that it can be corrected promptly by increases in $F \mathrm{I} \mathrm{O}_{2}$ (i.e. $0.24-0.40$ ), without major unexpected side-effects. While breathing $100 \% \mathrm{O}_{2}$, it is of note that, from a pathophysiological viewpoint, there is further worsening of $V^{\prime} \mathrm{A} / Q^{\prime}$, solely as a consequence of marked increase in the dispersion of blood flow. This suggests that HPV is attenuated even in the absence of accompanying pulmonary haemodynamic changes. Through the mechanisms of vascular recruitment and dilatation, the pulmonary vascular bed may redistribute blood flow without influencing standard flow-pressure outcomes, but still provoking further worsening in some of the markers of $V^{\prime} \mathrm{A} / Q^{\prime}$ imbalance.

In contrast, the distribution of alveolar ventilation decreases (improves) during mechanical ventilation but increases (worsens) during spontaneous breathing, possibly reflecting a different hypoxic vascular response related to ventilatory support, since blood flow can be redistributed to areas with high or low $V^{\prime} \mathrm{A} / Q^{\prime}$ ratios, respectively. Moreover, in patients with ASA needing mechanical ventilation, a moderate amount of increased intrapulmonary shunt is shown (below $10 \%$ of cardiac output) upon breathing $100 \% \mathrm{O}_{2}$ [21], an uncommon 
finding in patients with chronic obstructive and restrictive respiratory diseases [26]. This points to the development of reabsorption atelectasis and/or to a marked increase in regional blood flow of small pre-existing intrapulmonary shunts [21].

During high $F \mathrm{I}_{2} \mathrm{O}_{2}$, there were significant increases in $\mathrm{Pa}, \mathrm{O}_{2}(>60 \mathrm{kPa}(450 \mathrm{mmHg}))$ and also in $\mathrm{Pa}, \mathrm{CO}_{2}$, although much less dramatic (of the order of $0.4-0.7$ $\mathrm{kPa}(3-5 \mathrm{mmHg})$ ). Taken together, these arterial blood gas findings suggest further $V^{\prime} \mathrm{A} / Q^{\prime}$ worsening, although the additional influence of a Haldane effect is also plausible. In patients with COPD, irrespective of the need for mechanical ventilation, $100 \% \mathrm{O}_{2}$ breathing always results in deterioration (increase) in the dispersion of blood flow, without altering the basal modest levels of shunt, hence suggesting release of HPV [27]. However, in some critical cases of ASA, increases and decreases in $P \mathrm{a}, \mathrm{CO}_{2}$ have been reported with application and removal of $100 \% \mathrm{O}_{2}$, suggesting a depressant effect on ventilation similar to that observed in patients with COPD [2]. However, this behaviour appears to be similar to that shown by near-fatal cases of asthma during episodes of respiratory arrest [3], and may merely reflect profound alveolar hypoventilation due to extreme respiratory muscle fatigue.

Although some experimental studies have suggested that variations in $\mathrm{FI}, \mathrm{O}_{2}$ may influence airway responses to bronchoconstrictor and bronchodilator stimuli [28], acute hyperoxia does not enhance the immediate bronchodilator response to nebulized $\beta$-adrenergic agonists in stable asthmatic patients [29]. However, the potential influence of $100 \% \mathrm{O}_{2}$ breathing on airway tone and the response of $V^{\prime} \mathrm{A} / Q^{\prime}$ heterogeneity in patients with ASA should also be taken into account, as bronchial hyperresponsiveness can be minimized in patients with asthma [30]. A hyperoxic bronchodilator response could increase regional ventilation in poorly-ventilated alveolar units, hence increasing local blood flow and improving gas exchange. A local reduction of pulmonary blood flow without influencing the hypoxic vascular response has been observed in response to canine antigen challenge [31]. This would tend to reduce the impact of local $V^{\prime} \mathrm{A} / Q^{\prime}$ mismatch, other things being equal.

It has been shown experimentally in normal lungs that hypocapnia can cause a deterioration of $V^{\prime} \mathrm{A} / Q^{\prime}$ relationships, suggesting that HPV is abrogated; in contrast, hypercapnia does not result in significant changes in $V^{\prime} \mathrm{A} / Q^{\prime}$ heterogeneity [32]. In patients with severe acute respiratory failure needing mechanical ventilation, metabolic alkalosis further disturbs $V^{\prime} \mathrm{A} / Q^{\prime}$ imbalance; and, conversely, reversing this effect with hydrochloric acid $(\mathrm{HCl})$ results in an improvement in $\mathrm{Sa}_{\mathrm{a}} \mathrm{O}_{2}$ [33], possibly related to the $\mathrm{pH}$ of the circulating blood rather than to the nature of $\mathrm{HCl}$. The acidosis-induced amelioration of gas exchange has been attributed to a dual mechanism: firstly, to a shift of the oxyhaemoglobin dissociation curve caused by the Bohr effect; secondly, and more importantly, to an improvement of $V^{\prime} \mathrm{A} / Q^{\prime}$ mismatch, possibly by enhancing HPV through a redistribution of blood flow away from hypoxic lung areas. Altogether, these findings are compatible with the concept that acidosis and alkalosis, respectively, enhance and mitigate the hypoxic vascular response of the lungs [34]. Likewise, it has been shown that hypocapnia-induced
$V^{\prime} \mathrm{A} / Q^{\prime}$ imbalance in hyperventilated normal canine lungs is $\mathrm{pH}$-mediated and is not a function of $\mathrm{PCO}_{2} \mathrm{per}$ se [35].

The hypoxic pulmonary pressor tone was almost completely abrogated with elevation of $\mathrm{pH}$ to 7.60 by a metabolic alkalosis, and a respiratory alkalosis at a similar $\mathrm{pH}$ resulted in a $70 \%$ decrement of the HPV response [36]. Of equal importance, increases in extracellular pH may also adversely disturb pulmonary gas exchange by causing deterioration in pulmonary mechanics and the distribution of ventilation. Hypocapnia induces bronchoconstriction of airways of all sizes and reduces collateral ventilation, a mechanism of vital importance in the maintenance of the $V^{\prime} \mathrm{A} / Q^{\prime}$ balance [37]. Calcium channels are important both in hypocapnia-induced contraction of airway smooth muscle and hypoxic vascular contraction of the lungs. Because calcium channels are $\mathrm{pH}$-dependent, it has been hypothesized that changes in calcium influx may profoundly influence the underlying alkalosis-induced changes in $V^{\prime} \mathrm{A} / Q^{\prime}$ heterogeneity [35].

Approximately $90 \%$ of the variation in both $\mathrm{Pa}, \mathrm{O}_{2}$ and $P(\mathrm{~A}-\mathrm{a}), \mathrm{O}_{2}$ values is accounted for by $V^{\prime} \mathrm{A} / Q^{\prime}$ imbalance in patients with asthma [20]. However, baseline $\mathrm{Pa}, \mathrm{O}_{2}$ values can be considered exceptionally high considering the underlying degree of $V^{\prime} \mathrm{A} / Q^{\prime}$ inequality. This suggests that some well-known extrapulmonary factors, such as cardiac output or overall minute ventilation, or both, modulate $P \mathrm{a}_{1} \mathrm{O}_{2}$ in addition to $V^{\prime} \mathrm{A} / Q^{\prime}$ mismatch [38, 39]. In critical ASA patients, both cardiac output and minute ventilation tend to be increased for reasons that are not yet completely understood, thus optimizing the baseline values of $\mathrm{Pa}, \mathrm{O}_{2}$, which would otherwise be much lower due to the deleterious effects of $V^{\prime} \mathrm{A} / Q^{\prime}$ inequalities. This helps to increase $P \mathrm{a}_{\mathrm{a}} \mathrm{O}_{2}$ in patients with asthma, either at baseline or following therapeutic interventions with bronchodilators [1, 18].

This hyperkinetic status could be related, at least in part, to the increased levels of exhaled nitric oxide (NO) found in patients with ASA [40, 41]. High levels of exhaled NO, reflecting induction of NO synthase, may have proinflammatory effects, since NO is a potent vasodilator and can enhance plasma exudation from bronchial vessels. Patients with asthma show a greater $V^{\prime} \mathrm{A} / Q^{\prime}$ mismatch than patients with idiopathic pulmonary fibrosis [26] or heart failure [39]. However, $\mathrm{Pa}_{2} \mathrm{O}_{2}$ is much lower in the latter two conditions, usually due to a low cardiac output together with a mild-to-modest $V^{\prime} \mathrm{A} / Q^{\prime}$ heterogeneity, rather than as a consequence of extreme $V^{\prime} \mathrm{A} / Q^{\prime}$ mismatch alone. Although there are different mechanisms by which cardiac output can modulate pulmonary gas exchange, one of the most influential is via its effect on mixed venous oxygen tension $\left(P_{\bar{v}}, \mathrm{O}_{2}\right)$, since low cardiac output reduces $\mathrm{Pa}_{\mathrm{a}} \mathrm{O}_{2}$, other things being equal $[38,39]$.

As described above (see "Clinical framework"), the supposition that there is a peculiar dissociation between spirometry and gas exchange in asthma has been strengthened by more recent findings, in which differences in the time course and severity of bronchoconstriction and gas exchange were shown in patients with ASA according to whether they were admitted to hospital or discharged home [6]. Whilst hospitalized patients, in general, showed greater functional abnormalities than 


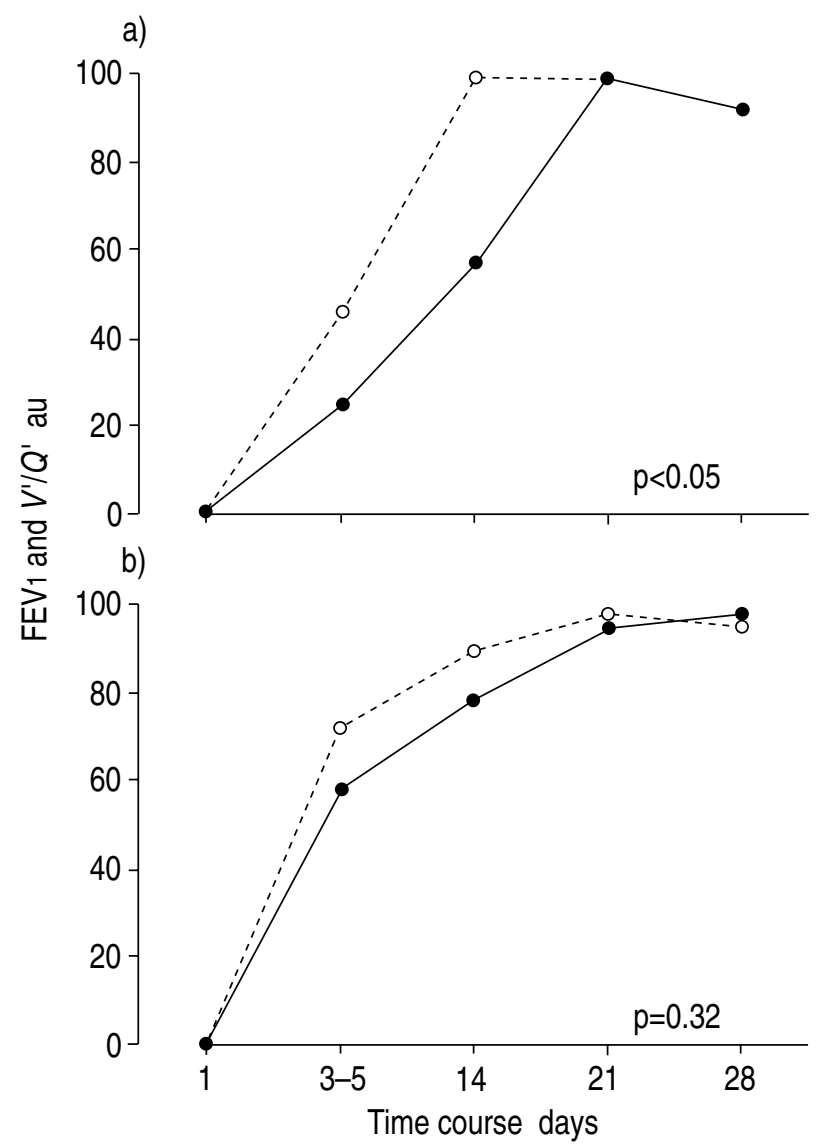

Fig. 3. - Time courses of improvement of FEV1 ( - - - - - ) and $V^{\prime} \mathrm{A} / Q^{\prime}$ inequality ( $\bullet-$ ) (as assessed by the dispersion of pulmonary blood flow): a) in patients with ASA in hospital; and b) in patients discharged home, while breathing room air. Variables are expressed in special arbitrary units (au): 100=the least abnormal value; $0=$ the most abnormal value. When hospitalized patients approached their maximal improvement in FEV1 at Week 2, $V^{\prime} \mathrm{A} / Q^{\prime}$ mismatch was still at $60 \%$ of its best value; by contrast, in discharged patients both spirometric and gas exchange abnormalities are similar and overlap. For definitions see legend to figure 1. (Taken with permission from [6]).

those sent home, only the former exhibited a more rapid and efficient recovery of spirometric changes compared to $V^{\prime} \mathrm{A} / Q^{\prime}$ inequalities (fig. 3). From these data, it can be postulated that patients with ASA who are discharged from the emergency room have less airway inflammatory changes and, with adequate therapy, improve more readily than those hospitalized, who in turn need more time to improve their functional status as they have more severe airway inflammation. These findings also support the concept that the more severe the attack of asthma, the more severe the obstructive narrowing in distal airways for a given degree of widespread airway narrowing. In a model of bronchoconstriction in the rabbit, similar $V^{\prime} \mathrm{A} / Q^{\prime}$ abnormalities to those shown in human asthma, but without increased airway resistance, have been simulated with nebulized isotonic saline [42]. Suffice it to say, that this reinforces the intriguing dissociation between spirometric and gas exchange findings in the setting of asthma. In contrast, in a sequential study in patients with an acute exacerbation of COPD, BARBERÀ et al. [23] observed a parallel behaviour of reduced maximal airflow rates and ventilation-perfusion disturbances.

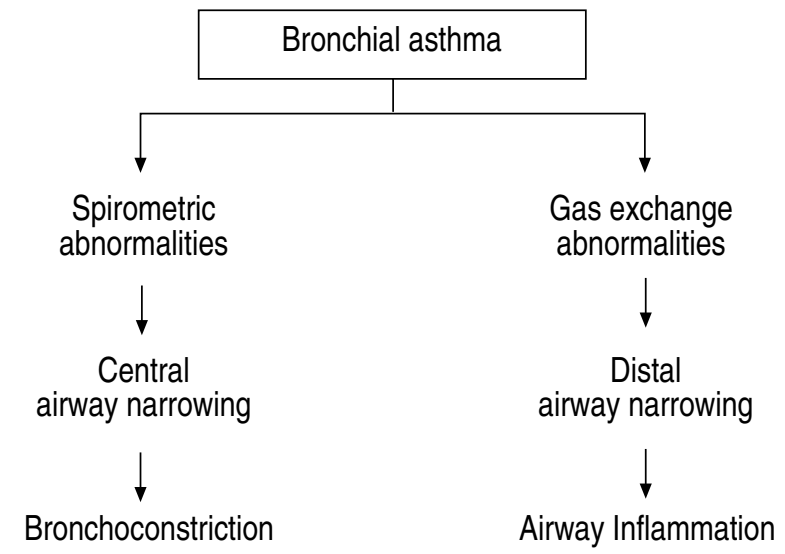

Fig. 4. - Pathophysiological interactions between airflow obstruction and gas exchange abnormalities in asthma.

Conceivably, these exciting findings reflect two different pathophysiological phenomena, and are consistent with the view that spirometric abnormalities reflect reduction of airway calibre in larger and middle-sized bronchi, whilst gas exchange abnormalities, more specifically $V^{\prime} \mathrm{A} / Q^{\prime}$ mismatch, refer predominantly to structural changes in distal, small airways. Thus, the latter changes could be more preferentially related to airway inflammation rather than to airflow obstruction per se (fig. 4). Overall, airway narrowing and pulmonary gas exchange are poorly related, both in individual patients and within a clinically similar category of asthma patients across the entire spectrum of asthma severity [20].

From this weak relationship between spirometry and gas exchange, it is clear that closer attention should be given to gas exchange abnormalities in the clinical management of these patients. Moreover, these findings indicate that spirometric data alone may provide neither an adequate delineation of clinical remission, nor a clear identification of those patients at risk of developing serious gas exchange deterioration [20]. Accordingly, it would be worthwhile to optimize knowledge of the relative importance of bronchoconstriction, inflammatory oedema, microvascular leakage and luminal mucous secretion within airways on gas exchange, because the pharmacological approach to these different pathophysiological features would clearly be different [20]. Nevertheless, it is extremely difficult to establish a true cause and effect relationship in human asthma to support this dissociation between airflow rates and gas exchange outcomes.

\section{Pathology}

Gas exchange disturbances are broadly consistent with postmortem lung findings in patients with ASA. In such patients, the degree of widespread bronchoconstriction, together with the varying airway inflammatory events, leads to the development of extensive areas of alveolar units in which ventilation is critically reduced but perfusion is maintained. As mentioned above (see "Pathophysiology"), increased intrapulmonary shunting is conspicuously negligible, possibly because the presence of collateral ventilation, from relatively undisturbed adjacent alveoli, preserves regional ventilation beyond the 
distal occluded airways. Two other mechanisms must also be borne in mind to explain the practical absence of shunt: firstly, the finding that airway obstruction can never be functionally complete; and, secondly, the exceptional efficacy of an active HPV.

In a seminal study, DunNILL [43] described the classical findings in patients dying of ASA. The airways were characteristically blocked by viscous, tenacious mucus physema was absent. Many airways were completely occluded by mucous plugging, composed of eosinophils and epithelial cells. Histologically, there was an increase in smooth airway muscle with hyperplasia and hybronchial wall cells, mainly eosinophils, was prominent and attributed to a transudation of oedematous fluid from the submucosa. Apart from the bronchial infiltration of eosinophils, the most extraordinary finding in the airway wall was "...the dilatation of the capillary blood vessels, often possessing rather swollen endothelial cells, closely applied to the basement membrane. The connective tissue in which these vessels lie consists of strands of widely separated collagen giving the impression of oedema. Moreover, the mucosa overlying these areas often shows oedema with separation of the cells..." (fig. 5). This quote, more than any other, appears to be one of the best descriptions of the abnormally increased airway vascular permeability in asthma.

Recent postmortem lung studies have further extended some of the correlations between pathology and both clinical and physiological findings. SAETta et al. [44] showed that the calibre of bronchioles was narrower than that of controls. Bronchioles of fatal asthmatic patients had increased luminal occlusion, smooth muscle thickness, and inflammatory infiltrate, and mononuclear cells and eosinophils contributed together to this within an acutely distended lung parenchyma; gross empertrophy in the major airways. Shedding of the ciliated

increased airway inflammation. This can be attributed to a combination of lesions that may occur during an inflammatory process, including vascular hyperaemia, plasma exudate, and inflammatory cell infiltrate. Another interesting finding was that part of the airway lumen was occluded and part was empty, such that these patients could be considered intermediate between those having mucous plugging and those showing dry airways, as described by REID [45]. Likewise, the muscular pulmonary arteries close to occluded and inflamed airways did not show the morphological changes of chronic hypoxia, and yet, there was an extreme inflammatory wall involvement that was particularly remarkable at the sites of contact of vessels and airways. This may support the notion that the severe inflammatory airway process spreads over the neighbouring vessel, as has been shown in patients with early COPD [46]. Whether or not these inflammatory changes may influence the hypoxic vascular response of these vessels remains to be determined.

Interestingly, using both endobronchial and transbronchial biopsies, KRAFT et al. [47] have recently demonstrated that, in patients with stable persistent asthma, the inflammatory response involves not only proximal airways but also distal airways, more specifically the alveolar tissue. Similarly, marked goblet cell hyperplasia in peripheral airways has been suggested as a predominant characteristic feature of patients who die of a severe attack of asthma [48]. Marked goblet cell hyperplasia may be involved in the intraluminal accumulation of large amounts of mucus in peripheral airways, and is likely to produce impairment of mucociliary transport and ion transport across the epithelium, and epithelial damage. Mucus retention is enhanced by a decrease in the number and length of the cilia in peripheral airways and in the rate of mucus transport with increasing airway branching [48].

It has been shown that "sud-

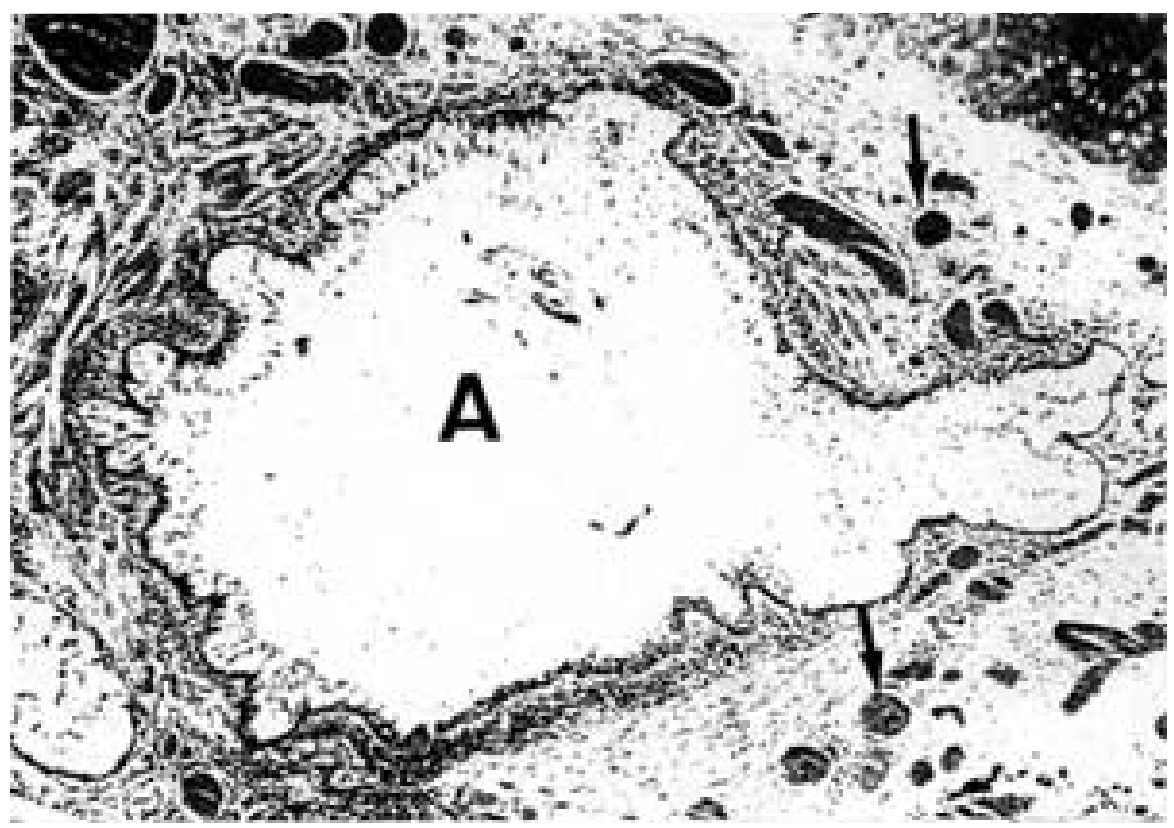

Fig. 5. - Histological section of airway (A) plugging in a patient with fatal asthma. There is thickening of the reticular basement membrane, a subepithelial zone of inflammatory cells surrounded by increased amounts of bronchial smooth muscle, and marked dilatation of the network of bronchial vessels and their engorgement with blood (arrows). Internal scale bar=100 $\mu \mathrm{m}$. (With kind permission of P.K. Jeffery, Lung Pathology Unit, National Heart \& Lung Institute, Imperial College, London, UK). den-onset" fatal asthma is immunologically distinct from "slow-onset" asthma, the latter having more eosinophils and fewer neutrophils in the airway submucosa. This suggests perhaps, two different pathological entities triggered by different inflammatory stimuli and resulting in distinct mechanisms of extreme airway narrowing [12]. These findings are akin to those shown by Azzawi et al. [49], who reported that levels of activated eosinophils were significantly higher in asthmatic patients whose fatal attack had a duration of more than $24 \mathrm{~h}$ compared with those who died suddenly. These sudden fatal episodes may occur against a background of persistent airway inflammation and structural derangement; moreover, those with the most extreme structural changes, such as mucous gland hypetrophy, will have the most devastating response [50]. Patients with fatal soybean asthma have diminished 
numbers of CD3+ and CD8+ T-cells in the airway epithelium and submucosa compared with fatal asthma cases [51]. However, there were no differences in the numbers of mast cells, eosinophils and neutrophils in relation to basal asthma severity or to the pattern of fatal attack. No differences have been observed between sudden-onset soybean epidemic asthma and slow-onset nonepidemic asthma patients both in the degree of severity and extent of $V^{\prime} \mathrm{A} / Q^{\prime}$ im-balance $[9,21]$.

\section{Pathobiology}

Despite the fact that overall airway structural changes concur essentially with the development of $V^{\prime} \mathrm{A} / Q^{\prime}$ abnormalities, the intrinsic mechanism by which $V^{\prime} \mathrm{A} / Q^{\prime}$ heterogeneity may occur in bronchial asthma still remains uncertain. It is currently believed that multiple mediators and their interactions are implicated in the pathogenesis of asthma. A vast literature exists to support the view that, in the inflamed airway, a large number of chemically different cell mediators are released from many sources. The way in which these substances provoke smooth muscle contraction and disrupt airway liquid balance illustrates a complex mechanism, whereby inflammation can cause influx of plasma into the airway wall and lumen by acting directly on endothelial and epithelial permeability.

Although new inflammatory mediators are continually being detected, numerous vasoactive agents have already been identified, including cell-derived mediators,
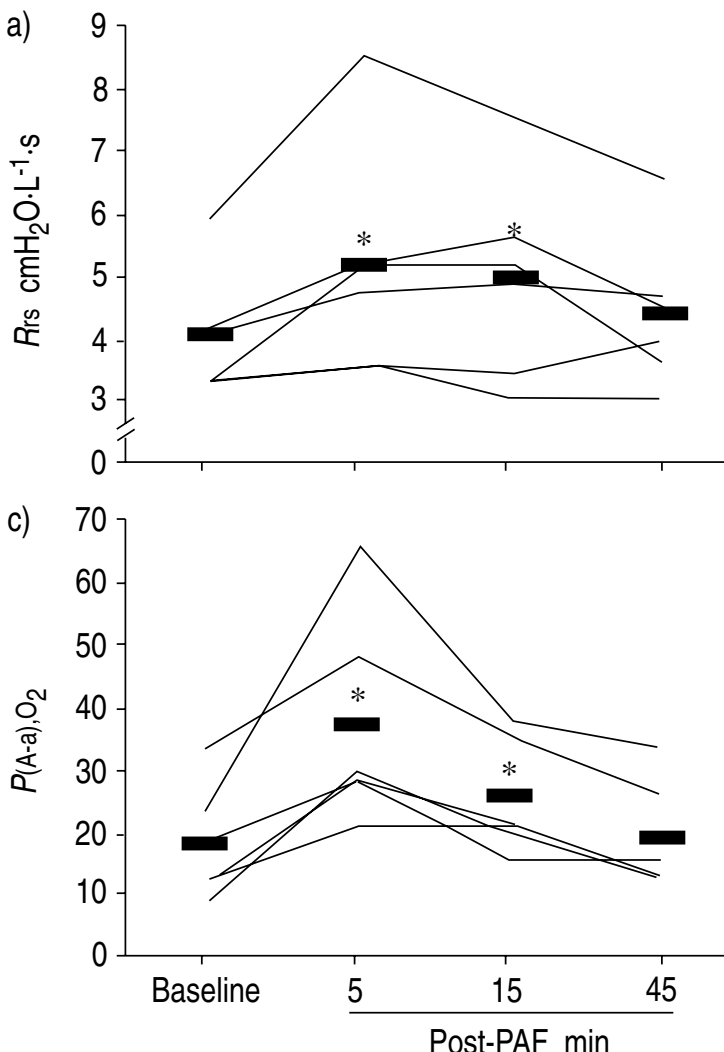

such as histamine, the cysteinyl leukotrienes, $\mathrm{LTC}_{4}, \mathrm{LTD}_{4}$ and $\mathrm{LTE}_{4}$, and PAF, and also neural-derived mediators, e.g. substance $\mathrm{P}(\mathrm{SP})$, neurokinin $\mathrm{A}$ and $\mathrm{B}$ (NKA, NKB), and calcitonin gene-related peptide (CGRP). PAF is a phospholipid that induces neutropenia, bronchoconstriction, and abnormal airway microvascular leakage, possibly through postcapillary venoconstriction in the tracheobronchial circulation. Thus, microvascular leakage of plasma is an inflammatory hallmark of paramount relevance in asthma, generally referred to as abnormally increased vascular permeability. A substantially increased number of PAF receptors are reported in the lungs of asthmatic individuals [52]. Collectively, all these findings lend further support to the view that PAF may be of particular relevance to the pathogenesis of asthma.

Because of its wide range of vascular effects, we postulated that PAF could disturb pulmonary gas exchange in patients with mild asthma. Challenge with a small dose $(12 \mu \mathrm{g})$ of PAF moderately increased the resistance of the respiratory system $(R \mathrm{rs})$ within 5 min after inhalation [53]. Simultaneously, $P \mathrm{a}_{1} \mathrm{O}_{2}$ decreased slightly, while there was a significant increase in the $P(\mathrm{~A}-\mathrm{a}), \mathrm{O}_{2}$, changes that were caused entirely by $V^{\prime} \mathrm{A} / Q^{\prime}$ heterogeneity, in a pattern similar to that commonly shown in patients with varying categories of asthma (fig. 6). Similar findings, although using a higher dose of PAF $(24 \mu \mathrm{g})$, were replicated in healthy individuals [54].

The question arises as to whether PAF-induced $V^{\prime} \mathrm{A} / Q^{\prime}$ imbalance may be related to bronchoconstriction or
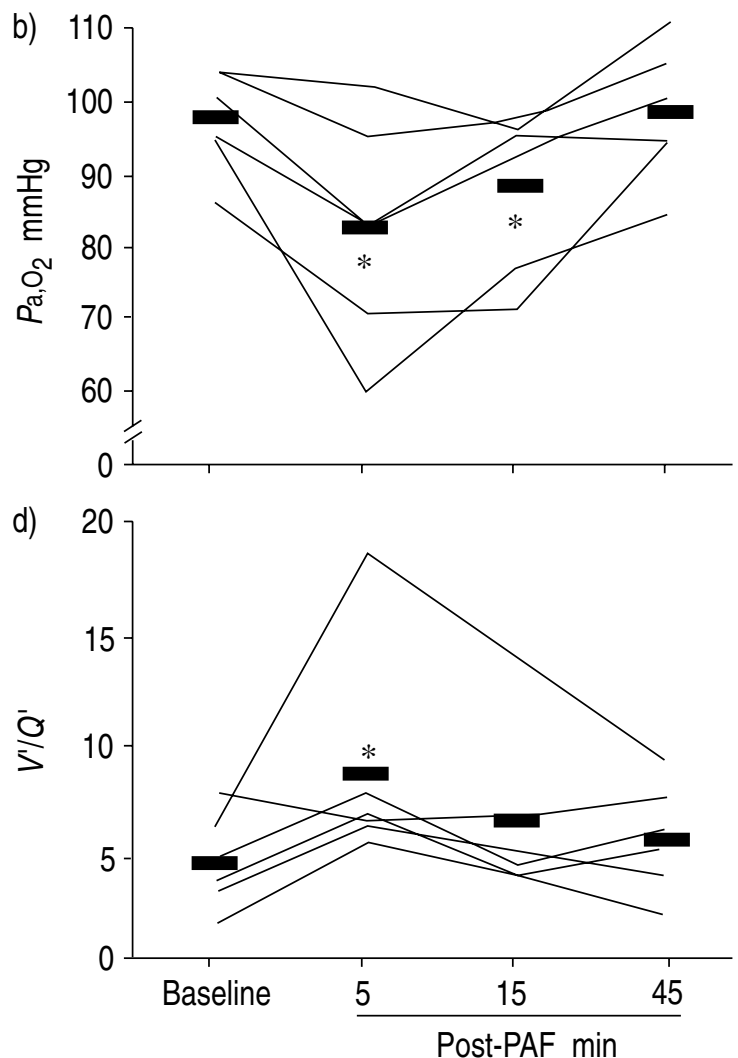

Fig. 6. - Individual time course of the four most relevant functional outcomes $\left(V^{\prime} \mathrm{A} / Q^{\prime}\right.$ mismatch is represented by a dimensionless overall index of $V^{\prime} \mathrm{A} / Q^{\prime}$ heterogeneity), altered by PAF challenge in six patients with mild asthma. a) resistance of the respiratory system (Rrs); b) arterial oxygen tension $\left.\left(\mathrm{P}_{\mathrm{a}}, \mathrm{O}_{2}\right) ; \mathrm{c}\right)$ alveolar-arterial difference in oxygen tension $\left.\left(P(\mathrm{~A}-\mathrm{a}), \mathrm{O}_{2}\right) ; \mathrm{d}\right)$ ventilation/perfusion $\left(V^{\prime} \mathrm{A} / Q^{\prime}\right)$ mismatch. $\mathrm{PAF}-i n d u c e d$ $V^{\prime} \mathrm{A} / Q^{\prime}$ relationships were extremely disturbed in one patient but less so in four, and were unchanged in the remaining patient. Solid bars represent means. *: $\mathrm{p}<0.05$ versus baseline. PAF: platelet-activating factor. (Taken with permission from [50]). 


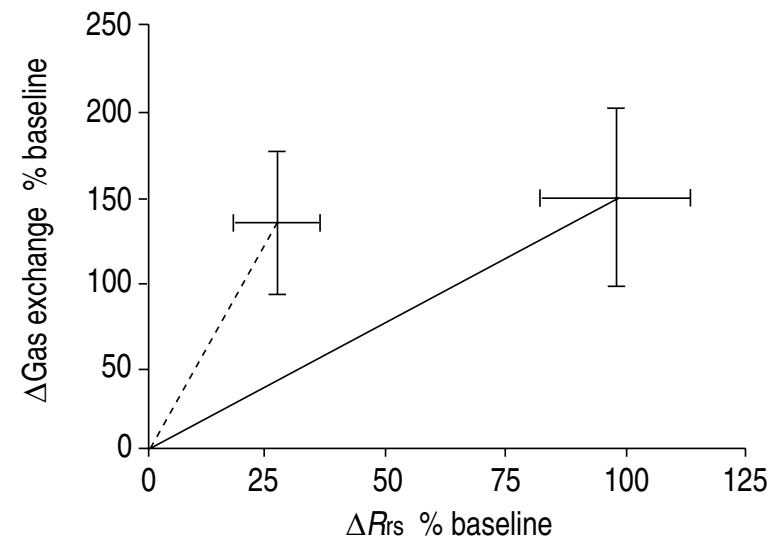

Fig. 7. - Plots of gas exchange indices and $R$ rs before and after PAF $(-)$ ) and methacholine $(\longrightarrow)$, expressed as percentage change $(\Delta \%)$ from baseline, in two populations of mild asthmatics. Values are presented as mean \pm SEM. Gas exchange responses, representing either increases in $P(\mathrm{~A}-\mathrm{a}), \mathrm{O}_{2}$ or $V^{\prime} \mathrm{A} / Q^{\prime}$ mismatch (as assessed by an overall index of $V^{\prime} \mathrm{A} / Q^{\prime}$ heterogeneity), were of the same order of magnitude. For further explanation, see text. For definitions see legend to figure 6. (Taken with permission from [50]).

altered microvascular-epithelial plasma exudation. It is of note, however, that the effects of inflammatory mediators on vascular permeability may, in part, induce bronchoconstriction through airway smooth muscle plasma-derived peptides. Therefore, both mechanisms may conceivably contribute together to widespread airway narrowing, hence leading to the development of $V^{\prime} \mathrm{A} / Q^{\prime}$ inequality. However, we suggest that the PAFinduced $V^{\prime} \mathrm{A} / Q^{\prime}$ abnormalities are related more to altered airway vascular permeability than to airway constriction, based on several pieces of information.

The first evidence is based on the comparison of the immediate effects of methacholine (MCh) [55] (which has a primary effect on airway smooth muscle) and PAF on $R$ rs and gas exchange markers (both arterial blood gas values and $V^{\prime} \mathrm{A} / Q^{\prime}$ inequalities) in patients with mild asthma (fig. 7). The slope was shifted rightwards and downwards after $\mathrm{MCh}$, as a markedly increased $R$ rs was associated with moderate worsening of gas exchange, but leftwards and upwards after PAF, as mild increases of $R$ rs combined with moderate deterioration of gas exchange. This indicates that MCh-induced intense bronchoconstriction per se does not cause much $V^{\prime} \mathrm{A} /$ $Q^{\prime}$ imbalance and, alternatively, that the effect of PAF on $V^{\prime} \mathrm{A} / Q^{\prime}$ relationships is unlikely to be explained on the basis of profound bronchoconstriction alone. Asthmatic patients develop greater airway obstruction after PAF challenge ( $30 \mu \mathrm{g}$ as a single dose) than normal subjects; however, $\mathrm{MCh}$ is much more sensitive than PAF at discriminating between asthmatic and healthy subjects [56].

Secondly, Rubin et al. [57] demonstrated that inhaled PAF, at doses similar to those we have used in healthy individuals [54], induced very little change in FEV1, of the order of $5 \%$ in normals and $10 \%$ in asthmatics, in comparison to relatively larger increases in more sensitive tests of airway dysfunction. Although PAF may produce airway narrowing by inducing bronchial wall oedema in addition to airway smooth muscle contraction, PAF has either no effect [58] or discrete but variable effects on the contraction of isolated human airways [59].
Thirdly, pretreatment with inhaled salbutamol (300 $\mu \mathrm{g})$ profoundly blocked PAF-induced effects on pulmonary neutrophil sequestration $[60,61], R$ rs and gas exchange disturbances, as well as systemic effects, namely, facial flushing, dyspnoea, feeling of warmth and cough, both in normal humans [62] and in patients with mild asthma [63]. These findings are unlikely to be interpreted as a smooth muscle relaxation alone, and contrast, in some aspects, with former data showing that a lower dose of salbutamol $(200 \mu \mathrm{g})$ in normal subjects failed to prevent PAF-induced disturbances [64]. Similarly, we have shown that pretreatment with inhaled ipratropium bromide, at a maximal bronchodilating dosage $(80 \mu \mathrm{g})$, antagonized only the PAF-induced increases of $R$ rs without altering neutropenia, gas exchange abnormalities or systemic effects [63].

If the effects of PAF in our asthma model are preferentially related to enhanced microvascular exudation of protein-rich plasma, then the protective role shown by salbutamol supports the view that the effect of this $\beta_{2}$-adrenergic agonist may be accomplished by preventing postcapillary venoconstriction of the bronchial circulation. Mediators that increase abnormal vascular permeability operate directly on the venular wall endothelium [65-68], possibly by altering normal cell-to-cell contact at distinct locations in the wall of the postcapillary venules (7-80 $\mu \mathrm{m}$ in diameter). The mechanism of this interendothelial gap (hole) formation has been widely accepted as a contractile phenomenon provoking wide clefts intercellularly, irrespective of the chemical composition of the mediator and whether the target is within or around the vessel.

These gap junctions are unique to endothelial changes after exposure to intravenous histamine [69]. The target cells for inflammatory mediators have, thus, been identified as venular endothelial cells, and their contraction has been suggested to support mediator-induced leakage of molecules and other substances. Non-sieved plasma would escape, via these holes in the venular wall, into extravascular sites, under the influence of the hydrostatic pressure gradient, hence abolishing the colloidal osmotic pressure gradient between the lumen of the microvessels and the interstitial space of the airway wall [68]. Bronchial blood flow changes will alter both the delivery of plasma and white cells and the microvascular hydrostatic pressure; similarly, the bronchial circulation may be extremely augmented in the inflamed airway, hence increasing the hydrostatic pressure in venules, resulting in local exudation and subsequent hyperaemia [70]. The hydrostatic pressure of the bronchial microvasculature depends both on the arterial and venous pressures and also on the ratio of post- to premicrovascular resistance [70].

Plasma exudate in the lumen of the airway in asthma may contribute to epithelial sloughing, disturbances in mucociliary transport, narrowing of distal airways and mucous plugging. Alternatively, exuded plasma may produce airway inflammation and constriction, since it includes potent mediators, and both chemoattractant ingredients and plasma proteins may facilitate the release of mediators by the numerous airway inflammatory cells involved in asthma in the presence of stimuli that would otherwise be harmless to the cells. Exuded plasma may, thus, by a direct effect on a variety of target 
cells and by recruitment and conditioning of inflammatory cells, enhance the process that escalates and sustains airway inflammation [67].

The relative absence of airway oedema usually observed in histological specimens may be explained, in part, by migration of plasma exudate into the airway lumen. Furthermore, abnormal airway microvascular leakage may amplify the bronchoconstrictor response by several mechanisms, such as increasing mucosal and/or submucosal thickness, interfering with the mechanical properties of the airway wall, uncoupling of the airway from the surrounding lung parenchyma, and/or filling of airway interstitial spaces, which together result in decreased calibre and increased resistance of the distal airways [69]. Nevertheless, it is not possible to differentiate the relative contribution of a leaky microvasculature, vascular engorgement and/or fluid shift from neighbouring cellular compartments to the extracellular engorgement [69]. Mild oedema within the airway wall would only marginally decrease the baseline airway calibre, but could profoundly increase airflow resistance during simultaneous bronchoconstriction. Experimental engorgement of the bronchial vasculature in a sheep model led to an increase in the vascular area in regions within and around the smooth muscle layer, whilst the associated reduction of luminal area only followed in the presence of airway smooth muscle tone [71]. This suggests that vascular hyperaemia induces a reflex effect on the airways and by itself plays only a marginal role on airway narrowing.

Likewise, the venular endothelial cell can be the target for drugs with antiexudative effects by direct vascular antipermeability mechanisms [72]. Bronchodilators, such as $\beta_{2}$-agonists and theophylline, may have the ability to minimize or antagonize airway inflammatory challengeinduced plasma exudation responses [73]. Conceivably, salbutamol, but not ipratropium bromide, could diminish hydrostatic pressure in the airway capillary network, hence reducing the degree of airway submucosal and adventitial swelling and the subsequent reduction of calibre in distal airways, resulting in $V^{\prime} \mathrm{A} / Q^{\prime}$ heterogeneity [63]. Moreover, salbutamol causes vasodilation that can increase the post- to premicrovascular resistance ratio of the bronchial circulation [70], hence decreasing the hydrostatic pressure and subsequent plasma exudation. Based on the hypothesis of endothelial contraction, salbutamol would, thus, have enhanced the ability of endothelial cells to minimize and/or close PAF-induced gap junctions, probably by facilitating their relaxation.

Although this contention also concurs with the inhibitory effects of $\beta_{2}$-agonists, in the guinea-pig, on PAFinduced $[74,75]$ and histamine-induced [76] disrupted airway permeability and acute plasma exudation, the efficacy of its potent airway relaxant influence on smooth muscle cannot be overlooked. The prevention of vascular leakage provoked by some drugs cannot be expected to have a rapid reversal, possibly because the rate of resolution of interstitial fluid is dependent mainly on the relatively slow lymphatic drainage. However, if the enhanced bronchomotor tone is dependent on a continuous supply of activated plasma proteins from adjacent leaky microvessels, then an anti-oedema effect might reverse the airway narrowing more rapidly.

Similarly, in the rat trachea, acute inhalation of a long-acting $\beta_{2}$-agonist induced a similar effective antioedema effect, whether plasma exudation was increased by cell-mediated mediators (PAF) or neuron-mediated mediators (SP) [75]. In contrast, another long-acting $\beta_{2^{-}}$ agonist, salmeterol, given over a 1 week period, did not inhibit the effects of PAF inhalation in normal individuals, possibly because of the induction of tachyphylaxis related to repeated dosing [77]. The absence of a transient increase of pulmonary artery pressure after PAF challenge in our PAF model both in normal man [54] and asthmatic patients [53] does not preclude a venoconstrictor effect of inhaled PAF, since, as mentioned above (see "Pathophysiology"), HPV can be attenuated without necessarily inducing pulmonary haemodynamic changes by itself [21].

Alternatively, the transient sequestration of neutrophils within the pulmonary circulation after PAF $[60$, 61], whose intrinsic mechanism remains to be determined, also provides indirect evidence of a release of the venular smooth muscle tone by salbutamol, hence reducing leucocyte transit time and their trapping within the pulmonary capillary network. By the same token, salbutamol could also prevent the ensuing release of other mediators into the pulmonary circulation, with potential local vasodilator effects that can disturb the $V^{\prime} \mathrm{A} / Q^{\prime}$ balance $[62,63]$. It is important to point out that, irrespective of the baseline $V^{\prime} \mathrm{A} / Q^{\prime}$ status, the wellknown pulmonary vasodilator effect of salbutamol can still be compatiable with its impact on further $V^{\prime} \mathrm{A} / Q^{\prime}$ worsening shown in ASA [18]. Adherence of white cells to the endothelium, with subsequent migration across the vascular wall, is a prominent feature of the inflammatory response. Although we ignore the potential effects of salbutamol on cellular adhesion at the endothelial level, other plausible mechanisms, such as lung hyperinflation due to PAF-induced bronchoconstriction causing capillary compression, are unlikely to play a key role. Development of areas of high $V^{\prime} \mathrm{A} / Q^{\prime}$ has never been observed, either in normals [54] or asthmatics [53] after inhalation of PAF; neither has diffusion limitation for $\mathrm{O}_{2}$ potentially induced by neutrophil lung sequestration. Finally, the abolition by salbutamol of the PAF-induced systemic effects, attributed to the subsequent release of other substances possibly derived from neutrophils, could also be related to its preventive effects on pulmonary neutrophil kinetics.

Increased plasma levels of PAF have been documented during mild exacerbations of asthma both in adults [78] and children [79], whereas decreased in vivo and in vitro productions of PAF have been shown in children after immunotherapy [79]. Moreover, we have seen the salutary effect of a new PAF receptor antagonist, SR 27417A, on PAF-induced lung function abnormalities, including systemic effects and neutropenia (unpublished data). These findings confirm that these types of drugs specifically antagonize leakage produced by corresponding agonists. However, because postcapillary venules harbour specific receptors for a wide variety of inflammatory mediators, it is unlikely that a single mediator antagonist alone can display an effective overall anti-exudative therapeutic response in asthma. The efficacy shown by SR 27417A is at variance with the apparent negative data formerly observed with other classes of PAF antagonist, which did not provide definite 
evidence that PAF is a vital mediator in asthma [80]. This suggests that the effects of PAF antagonists should be investigated in other categories of asthma, for instance in patients with ASA [81], or that other functional outcomes, such as gas exchange markers, should be used to better identify the potential anti-oedema effect of the airways.

\section{Concluding remarks}

Both in normal subjects and in patients with asthma, challenge with platelet-activating factor induces remarkable gas exchange abnormalities due to ventilation/ perfusion mismatch, a hallmark of primary clinical relevance in acute severe asthma, similar to those detected in patients with moderate-to-severe categories of asthma. Of equal importance, a highly recommended cornerstone of the therapeutic guidelines of asthma, salbutamol, but not ipratropium bromide, has been shown to be highly effective in inhibiting all platelet-activating factor-induced systemic, neutropenic, lung mechanical and gas exchange responses. Collectively, these findings could support the supposition that endogenous release of platelet-activating factor may be incriminated in the gas exchange disturbances seen during acute severe asthma.

The generally accepted criteria for judging the relevance of a mediator in asthma should be: 1) produced by cells involved in the asthmatic damage; 2) capable of mimicking some aspects of its pathophysiology; 3) recoverable naturally or induced by disease; and 4) ameliorating the disease through inhibition of its action or synthesis [82]. This tentative pathogenic notion of platelet-activating factor needs to be further investigated to thoroughly support whether or not this inflammatory mediator plays a putative role in the pathobiology of asthma, a hypothesis often invoked but never conclusively proven.

\section{References}

1. Rodriguez-Roisin R, Roca J. Contributions of multiple inert gas elimination technique to pulmonary medicine. 3. Bronchial asthma. Thorax 1994; 49: 1027-1033.

2. McFadden ER Jr, Hejal R. Asthma. Lancet 1995; 345: $1215-1220$.

3. Molfino NA, Nannini LJ, Martelli AN, Slutsky AS. Respiratory arrest in near-fatal asthma. $N$ Engl J Med 1991; 324: 285-288.

4. Rebuck AS, Read J. Assessment and management of severe asthma. Am J Med 1971; 51: 788-798.

5. Roca J, Ramis LI, Rodriguez-Roisin R, Ballester E, Montserrat JM, Wagner PD. Serial relationships between ventilation-perfusion inequality and spirometry in acute severe asthma requiring hospitalization. Am Rev Respir Dis 1988; 137: 1055-1061.

6. Ferrer A, Roca J, Wagner PD, Lopez FA, RodriguezRoisin R. Airway obstruction and ventilation-perfusion relationships in acute severe asthma. Am Rev Respir Dis 1993; 147: 579-584.

7. Mountain RD, Sahn SA. Clinical features and outcome in patients with acute asthma presenting with hypercapnia. Am Rev Respir Dis 1988; 138: 535-539.
8. Wasserfallen JB, Schaller MD, Feihl F, Perret C. Sudden asphyxic asthma: a distinct entity? Am Rev Respir Dis 1990; 142: 108-111.

9. Ferrer A, Torres A, Roca J, Sunyer J, Antó JM, RodriguezRoisin R. Characteristics of patients with soybean dustinduced acute severe asthma requiring mechanical ventilation. Eur Respir J 1990; 3: 429-433.

10. Murray V, Venables K, Laing-Morton T, Partridge M, Williams D. Epidemic of asthma possibly related to thunderstorms. BMJ 1994; 309: 131-132.

11. O'Hallaren MT, Yunginger JW, Offord KP, et al. Exposure to an aeroallergen as a possible precipitating factor in respiratory arrest in young patients with asthma. $N$ Engl J Med 1991; 324: 359-363.

12. Sur S, Crotty TB, Kephart GM, et al. Sudden-onset fatal asthma. A distinct entity with few eosinophils and relatively more neutrophils in the airway submucosa. $A m$ Rev Respir Dis 1993; 148: 713-719.

13. Rodriguez-Roisin R, Torres A, Agusti AGN, Ussetti P, Agusti-Vidal A. Subconjunctival haemorrhage: a feature of acute severe asthma. Postgrad Med J 1983; 61: 579-581.

14. Dimond JP, Palazzo MGA. An unconscious man with asthma and a fixed, dilated pupil. Lancet 1997; 349: 98.

15. McFadden ER Jr, Lyons HA. Arterial blood gas tensions in asthma. $N$ Engl J Med 1968; 278: 1027-1032.

16. Tai E, Read J. Arterial-blood gas tension in asthma. Lancet 1967; i: 644-646.

17. Mihatsch W, Geelhoed GC, Landau LI, LeSouëf PN. Time course of change in oxygen saturation and peak expiratory flow rate in children admitted to hospital with acute asthma. Thorax 1990; 45: 438-441.

18. Ballester E, Reyes A, Roca J, Guitart R, Wagner PD, Rodriguez-Roisin R. Ventilation-perfusion mismatching in acute severe asthma: effects of salbutamol and 100\% oxygen. Thorax 1989; 44: 258-267.

19. Roca J, Wagner PD. Contributions of multiple inert gas elimination technique to pulmonary medicine. 1. Principles and information content of the multiple inert gas elimination technique. Thorax 1994; 49: 815-824.

20. Wagner PD, Hedenstierna G, Rodriguez-Roisin R. Gas exchange, expiratory flow obstruction and the clinical spectrum of asthma. Eur Respir J 1996; 9: 1278-1282.

21. Rodriguez-Roisin R, Ballester E, Torres A, Roca J, Wagner PD. Mechanisms of abnormal gas exchange in patients with status asthmaticus needing mechanical ventilation. Am Rev Respir Dis 1989; 139: 732-739.

22. Lee LN, Ueno O, Wagner PD, West JB. Pulmonary gas exchange after multiple airway occlusion by beads in the dog. Am Rev Respir Dis 1989; 140: 1216-1221.

23. Barberà JA, Roca $\mathrm{J}$, Ferrer $\mathrm{A}$, et al. Mechanisms of abnormal gas exchange during acute exacerbations of chronic obstructive pulmonary disease. Eur Respir $J$ 1997; 10: 1285-1291.

24. West JB, Dollery CT, Naimark A. Distribution of blood flow in isolated lung: relation to vascular and alveolar pressures. J Appl Physiol 1964; 19: 713-724.

25. Freyschuss U, Hedelin G, Hedenstierna G. Ventilationperfusion relationships during exercise-induced asthma in children. Am Rev Respir Dis 1984; 130: 888-894.

26. Agustí AGN, Barberà JA. Contributions of multiple inert gas elimination technique to pulmonary medicine. 2. Chronic pulmonary disease: chronic obstructive pulmonary disease and idiopathic pulmonary fibrosis. Thorax 1994; 49: 924-932.

27. Rodriguez-Roisin R, Roca J. Gas exchange in COPD. In: Calverley PMA, Pride NB, eds. Chronic Obstructive 
Pulmonary Disease. London, Chapman \& Hall, 1994; pp. 161-184.

28. Clayton RA, Nally JE, Thomson NC, McGrath JC. The effect of oxygen tension on responses evoked by methacholine and bronchodilators in isolated bovine bronchial rings. Pulm Pharmacol 1996; 9: 123-128.

29. Dagge KD, Thomson LJ, Ramsay SG, Thomson NC. Effect of acute hypoxia on the bronchodilator response to salbutamol in stable asthmatic patients. Thorax 1996; 51: 853-854.

30. Inoue $\mathrm{H}$, Inoue $\mathrm{C}$, Okayama $\mathrm{M}$, Sekizawa $\mathrm{K}$, Hida $\mathrm{W}$, Takishima Y. Breathing 30 percent oxygen attenuates bronchial responsiveness to methacholine in asthmatic patients. Eur Respir J 1989; 2: 506-512.

31. Grant BJB, Fortune JB, West JB. Effect of local antigen inhalation and hypoxia on lobar blood flow in allergic dogs. Am Rev Respir Dis 1980; 122: 39-46.

32. Domino KB, Swenson ER, Polissar NL, Lu Y, Eisenstein $\mathrm{BL}$, Hlastala MP. Effect of inspired $\mathrm{CO}_{2}$ on ventilation and perfusion heterogeneity in hyperventilated dogs. $J$ Appl Physiol 1993; 75: 1306-1314.

33. Brimioulle $\mathrm{S}$, Kahn RJ. Effects of metabolic acidosis on pulmonary gas exchange. Am Rev Respir Dis 1990; 141: $1185-1189$.

34. Nattie EE. Gas exchange in acid-base disturbances. In: Fahri LE, Tenney SM, eds. Handbook of Physiology. Vol. 4. The Respiratory System: Gas Exchange. Bethesda; American Physiological Society, 1987; pp. 421-438.

35. Domino KB, Swenson ER, Hlastala MP. Hypocapniainduced ventilation-perfusion mismatch: a direct $\mathrm{CO}_{2}$ or pH-mediated effect? Am J Respir Crit Care Med 1995; 152: 1534-1539.

36. Brimioulle S, Lejeune P, Vachiéry JL, Leeman M, Mélot C, Naeije R. Effect of acidosis and alkalosis on hypoxic pulmonary vasoconstriction in dogs. Am J Physio 1990; 258: H347-H353.

37. Traystman RJ, Terry PB, Menkes HA. Carbon dioxide, a major determinant of collateral ventilation. $J$ Appl Physiol: Respirat Environ Exercise Physiol 1978; 45: 69-74.

38. Rodriguez-Roisin R, Wagner PD. Clinical relevance of ventilation-perfusion inequality determined by inert gas elimination. Eur Respir J 1990; 3: 469-482.

39. Wagner PD, Rodriguez-Roisin R. Clinical advances in pulmonary gas exchange. Am Rev Respir Dis 1991; 143: 883-888.

40. Kharitonov SA, Yates D, Robbins RA, Logan-Sinclair $\mathrm{R}$, Shinebourne EA, Barnes PJ. Increased nitric oxide in exhaled air of asthmatic patients. Lancet 1994; 343: $133-135$.

41. Massaro AF, Gaston B, Kita D, Fanta C, Stamler JS, Drazen JM. Expired nitric oxide levels during treatment of acute asthma. Am J Respir Crit Care Med 1995; 152: 800-802.

42. Lagerstrand L, Dahlbäck M, Hedenstierna G. Gas exchange during simulated airway secretion in the anaesthesized rabbit. Eur Respir J 1992; 5: 1215-1222.

43. Dunnill MS. The pathology of asthma, with special reference to changes in the bronchial mucosa. J Clin Pathol 1960; 13: 27-33.

44. Saetta M, Di Stefano A, Rosina C, Thiene G, Fabbri LM. Quantitative structural analysis of peripheral airways and arteries in sudden fatal asthma. Am Rev Respir Dis 1991; 143: 138-143.

45. Reid LM. The presence or absence of bronchial mucus in fatal asthma. Allergy J Clin Immunol 1987; 80 (Suppl.): 415-419.
46. Barberà JA, Riverola $\mathrm{A}$, Roca $\mathrm{J}$, et al. Pulmonary vascular abnormalities and ventilation-perfusion relationships in mild chronic obstructive pulmonary disease. Am J Respir Crit Care Med 1994; 149: 423-429.

47. Kraft M, Djukanovic R, Wilson S, Holgate ST, Martin RJ. Alveolar tissue inflammation in asthma. Am J Respir Crit Care Med 1996; 154: 1505-1510.

48. Aikawa T, Shimura S, Sasaki H, Ebina M, Takishima T. Marked goblet cell hyperplasia with mucus accumulation in the airways of patients who died of acute severe asthma attack. Chest 1992; 101: 916-921.

49. Azzawi M, Johnston PW, Majumdar S, Kay AB, Jeffery PK. T-lymphocytes and activated eosinophils in airway mucosa in fatal asthma and cystic fibrosis. Am Rev Respir Dis 1992; 145: 1477-1482.

50. Carroll N, Carello S, Cooke C, James A. Airway structure and inflammatory cells in fatal attacks of asthma. Eur Respir J 1996; 9: 709-715.

51. Synek M, Antó JM, Beasley R, et al. Immunopathology of fatal soybean dust-induced asthma. Eur Respir $J$ 1996; 9: 54-57.

52. Shirasaki H, Nishikawa M, Adcock JM, et al. Expression of platelet-activating factor receptor mRNA in human and guinea-pigs. Am J Respir Cell Mol Biol 1994; 10: 533-537.

53. Félez MA, Roca J, Barberà JA, et al. Inhaled plateletactivating factor worsens gas exchange in mild asthma. Am J Respir Crit Care Med 1994; 150: 369-373.

54. Rodriguez-Roisin R, Félez MA, Chung FK, et al. Platelet-activating factor causes ventilation-perfusion mismatch in humans. J Clin Invest 1994; 93: 188-194.

55. Rodriguez-Roisin R, Ferrer A, Navajas D, Agustí AGN, Wagner PD, Roca J. Ventilation-perfusion mismatch after methacholine challenge in patients with mild bronchial asthma. Am Rev Respir Dis 1991; 144: 88-94.

56. Louis RE, Radermecker MF. Acute bronchial obstruction following inhalation of PAF in asthmatic and normal subjects: comparison with methacholine. Eur Respir $J$ 1996; 9: 1414-1420.

57. Rubin AE, Smith LJ, Patterson R. The bronchoconstrictor properties of platelet-activating factor in humans. Am Rev Respir Dis 1987; 136: 1145-1151.

58. Schellenberg RR. Airway responses to platelet-activating factor. Am Rev Respir Dis 1987; 136: S28-S32.

59. Johnson PRA, Black JL, Armour CL. Platelet-activating factor-induced contraction of human isolated bronchus. Eur Respir J 1992; 5: 970-974.

60. Tam FWK, Clague J, Dixon CM, et al. Inhaled plateletactivating factor causes pulmonary neutrophil sequestration in normal humans. Am Rev Respir Dis 1992; 146: 1003-1008.

61. Masclans JR, Barberà JA, MacNee W, et al. Salbutamol reduces pulmonary neutrophil sequestration of plateletactivating factor in humans. Am J Respir Crit Care Med 1996; 154: 529-532.

62. Roca J, Félez MA, Chung KF, et al. Salbutamol inhibits pulmonary effects of platelet-activating factor in man. Am J Respir Crit Care Med 1995; 151: 1740-1745.

63. Díaz O, Barberà JA, Marrades R, Chung KF, Roca J, Rodriguez-Roisin R. Inhibition of PAF-induced gas exchange defects by beta-adrenergic agonists in mild asthma is not due to bronchodilation. Am J Respir Crit Care Med 1997; (In press).

64. Chung KF, Dent G, Barnes PJ. Effects of salbutamol on bronchoconstriction, bronchial hyperresponsiveness, and leucocyte responses induced by platelet-activating factor in man. Thorax 1988; 44: 102-107. 
65. McDonald DM. Neurogenic inflammation in the respiratory tract: actions of the sensory nerve mediators on blood vessels and epithelium of the airway mucosa. Am Rev Respir Dis 1987; 136: S65-S67.

66. McDonald DM. The ultrastructure and permeability of tracheobronchial vessels in health and disease. Eur Respir J 1990; 3 (Suppl. 12): 572s-585s.

67. Persson CGA. Role of plasma exudation in asthmatic airways. Lancet 1986; ii: 1126-1128.

68. Persson CGA, Erjefält JS, Andersson M, Greiff L, Svensson C. Extravasation, lamina propria and lumenal entry of bulk plasma in mucosal defence, inflammation and repair. Pulm Pharmacol 1996; 9: 129-139.

69. Yager D, Butler J, Bastacky J, Israel E, Smith G, Drazen JM. Amplification of airway constriction due to liquid filling of airway interstices. J Appl Physiol 1989; 66: 2873-2884.

70. Persson CGA. Plasma exudation and asthma. Lung 1988; 166: 1-23.

71. Wagner EW, Mitzner W. Effects of bronchial vascular engorgement on airway dimensions. J Appl Physiol 1996; 81: 293-301.

72. Erjefält JS, Svensjö E. Vascular responses and their suppression: drugs interfering with venular permeability. In: Bonta IL, Bray MA, Parnham MJ, eds. Handbook of Inflammation. Vol. 5. Amsterdam, Elsevier, 1985; pp. 61-82.

73. Erjefält JS, Persson CGA. Pharmacological control of plasma exudation into tracheobronchial airways. $A m$ Rev Respir Dis 1991; 143: 1008-1014.

74. Sulakvelidze I, McDonald DM. Anti-edema action of formoterol in rat trachea does not depend on capsaicinsensitive sensory nerves. Am J Respir Crit Care Med 1994; 149: 232-238.

75. Sakamoto T, Barnes PJ, Chung KF. Effect of $\beta_{2-}$ adrenoceptor agonists against platelet-activating factorinduced airway microvascular leakage in the guinea-pig. Agents Actions 1993; 40: 50-56.

76. Tokuyama K, Lötvall JO, Löfdahl CG, Barnes PJ, Chung KF. Inhaled formoterol inhibits histamine-induced airflow obstruction and airway microvascular leakage. Eur J Pharmacol 1991; 193: 35-39.

77. Spring J, Johnston SR, Seale J, Ind PW. Failure of salmeterol to inhibit white cell responses and bronchoconstriction induced by platelet-activating factor. Thorax 1992; 47: 948-951.

78. Kurosawa M, Yamashita T, Kurimoto F. Increased levels of platelet-activating factor in bronchial asthmatic patients with active symptoms. Allergy 1994; 49: 6063.

79. Kue-Hsiung H, Cheng-Koon Ng. Increased plasma platelet-activating factor in children with acute asthmatic attacks and decreased in vivo and in vitro production of platelet-activating factor after immunotherapy. $J$ Allergy Clin Immunol 1993; 91: 650-657.

80. Kuitert L, Barnes NC. PAF and asthma: time for appraisal? Clin Exp Allergy 1995; 25: 1159-1162.

81. Nadel JA. Genetics reveals importance of platelet-activating factor in asthma and possibly other inflammatory states. J Clin Invest 1996; 97: 2689-2690.

82. Drazen J. What are the clinical benefits of a selective approach? Eur Respir Rev 1994; 6: 402-404. 